\title{
ANALYZE THE IMPACT OF DISTANCE BETWEEN THE OBJECT AND THE MATRIX OF THE SHOOTING TECHNIQUES ON THE COEFFICIENT OF THE TRANSFORMATION FOR OBTAINING DIMENSIONS FEATURES BY PHOTOGRAMMETRIC METHOD
}

\author{
Georgi Georgiev \\ Faculty of Technics and Techology of Yambol, Trakia University of Stara Zagora \\ Graf Ignatiev 38, 8600 Yambol, Bulgaia \\ mobile: +359887185869, e-mail: georgi.georgiev@trakia-uni.bg
}

\begin{abstract}
The use of photogrammetric method for determining the geometric parameters of objects of engineering practice is still limited due to a number of factors. One of them comes from the nature of the process capturing and defining the regime elements. For the rapid determination of the dimensions of the digital model should be calculated coefficient of performance, taking into account the impact of various factors. This article discussed the influence of the distance from the object to capture technique

Keywords: photogrammetry, non-contact measurement, photography, measurement accuracy.
\end{abstract}

\section{INTRODUCTION}

Photogrammetry is a method in which based on the initial information received from one or more photographs of the physical object is obtained digital model of the object $[1,5]$. This model can be used for various purposes - for measurement of dimensions, manufacturing of the object, simulating the working processes, etc. Photogrammetry has found wide application in various areas - mapping, surveying, restoration of historical monuments, etc., but as non-contact method for obtaining geometric and dimensional characteristics of relatively small objects, such as machine parts, do not yet finds due to number difficulties [6, 7, 8].

Photogrammetric determination of geometric dimensions is a combination of two activities: capturing and measuring. On these activities are affected many and varied in nature factors that have complex and sometimes mixed impact on the accuracy in determining the geometric properties of objects. They occur in the various stages of the process in photogrammetric work:

- calibration - at this stage a reference value by which determining the searched geometric dimension is obtained. To obtain the required accuracy is desirable that the conditions under which the calibration is carried out to be identical with the conditions under which recording is performed, as the best results are obtained if the calibration and recording are performed simultaneously;

- capturing - At this stage digital image of the object whose geometric dimensions need to be determined is obtained. Here the main precision characteristics depend on the quality of the shooting technique (optics, focal length) and the conditions under which shooting are done;

- reading value measurement - processing of geometric data is performed so as to obtain the corresponding value of the dimension of the object. Since the volume of the computational activity is large commonly software is used [2]. 


\section{IRTITE}

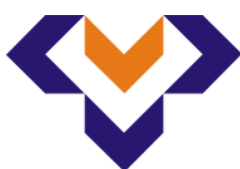

Ipplied Reseitrones in Technics, Technologies and Bductition

Journal of the Faculty of Technics and Technologies, Trakia University https:///sites.google.com/a/trakia-uni.bg/artte/

When the goal of the work is measurement from a single image, it is appropriate calibration and shooting are carried out simultaneously where necessary the requirement the caliber and the measured part lie in one plane toward the direction of the shooting to be executed.

If necessary measurement of several sizes from more than one photo first it is necessary to perform a calibration, then in the same (or as close as possible) conditions to be executed the shooting of the detail.

In this providing requirement the detail and the caliber to lie in one plane is embarrassed. This will affect the accuracy with which the dimensions of the model are determined.

It is necessary to conduct a study to find factors and determine their impact on the dimensions of the received model by introducing a coefficient of performance.

\section{THEORETICAL TREATMENT}

Despite the wide variety of factors that influence the dimensions and accuracy of the photogrammetric image it is established that they are most dependent on the distance between shooting object, optical elements and the light-sensitive sensor of the shooting technique $[1,5]$.

The resulting image has a height $Y 2$ (Fig.1), which is dependent on the height of the real object $\mathrm{Y} 1$, the distance between the object lens and $\mathrm{X} 1$ and between the lens and the matrix on which the image is projected $\mathrm{X} 2$. Between them dependence, satisfying equality exists:

$$
\mathrm{X} 1 / \mathrm{Y} 1=\mathrm{X} 2 / \mathrm{Y} 2
$$

The mathematical relation between the image and the actual object is expressed by the coefficient of performance which is the ratio between the geometric dimensions of the image on the sensor and the actual size of the object. From this definition and the scheme of Figure 1 it follows that:

$$
\mathrm{KT}_{\mathrm{T}}=\mathrm{Y} 2 / \mathrm{Y} 1=\mathrm{X} 2 / \mathrm{X} 1
$$

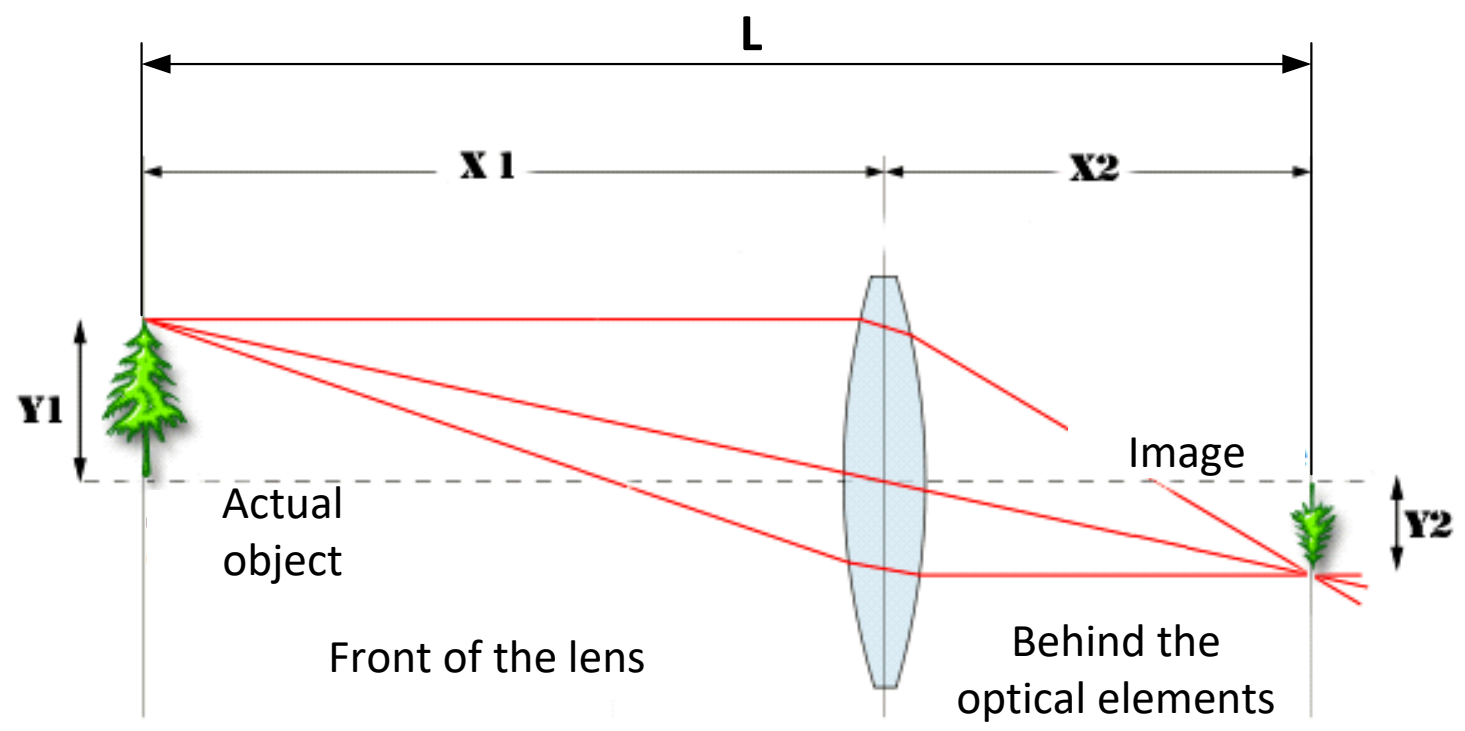

Figure 1. Principal scheme for converting the shooting object from optical elements during photographing: $L$ - distance from the object to the matrix of the shooting techniques; $X 1$ distance from the object to the lens; $X 2$ - focal length; $Y 1$ - size of the object; $Y 2$ - image size on the matrix 


\section{ARTITE

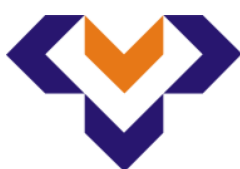 \\ Ipplied Researlohes in Technics, Technologies and Bductition \\ Journal of the Faculty of Technics and Technologies, Trakia University https://sites.google.com/a/trakia-uni.bg/artte/}

The dimension of this factor depends on the capabilities of the shooting equipment and the reading method of the size $\mathrm{Y} 2$ from the matrix. Depending on what $\mathbf{K}_{\mathbf{T}}$ has dimension pixel per millimeter $[\mathrm{px} / \mathrm{mm}]$ or millimeter per millimeter $[\mathrm{mm} / \mathrm{mm}]$, i.e. it has dimensionless value. The second case is primarily used in film cameras, but new models digital devices and cameras more common have matrices in which image sizes are reported in pixels. On the magnitude of the coefficient of performance influences number of factors that need to be investigated experimentally:

$$
\mathrm{K}_{\mathrm{T}}=f\left(K_{L}, K_{f}, \mathrm{~K}_{\text {осв. }} \cdots \ldots K_{n}\right)
$$

where $K_{L}, K_{f}, K_{\text {осв. } \ldots \ldots . . .} K_{n}$ are the correction coefficients of the various factors influencing the formation of the value of $K_{\mathrm{T}}$ : distance from the object to the matrix of the shooting techniques $\mathrm{L}$, focal length $\mathrm{f}$, capturing light, the dimensions of the matrix of used photographic equipment, used software for photo editing and reading dimensions, quality of the surface of the subject, shooting resolution of the monitor and others. [3, 4].

If the value of $\mathrm{K}_{\mathrm{T}}$, taking into account the influence factors under certain conditions of conducting the shooting, is determined, it is possible to construct a calibration characteristic, in which with known distance to the object $X 1$, to allow rapid determination of the $\mathrm{K}_{\mathrm{T}}$ (respectively the size $\mathrm{Y} 1$ ) in the case of the shooting conditions identical or similar to those in which the study was conducted for $\mathrm{K}_{\mathrm{T}}$. This will substantially reduce the time for obtaining a

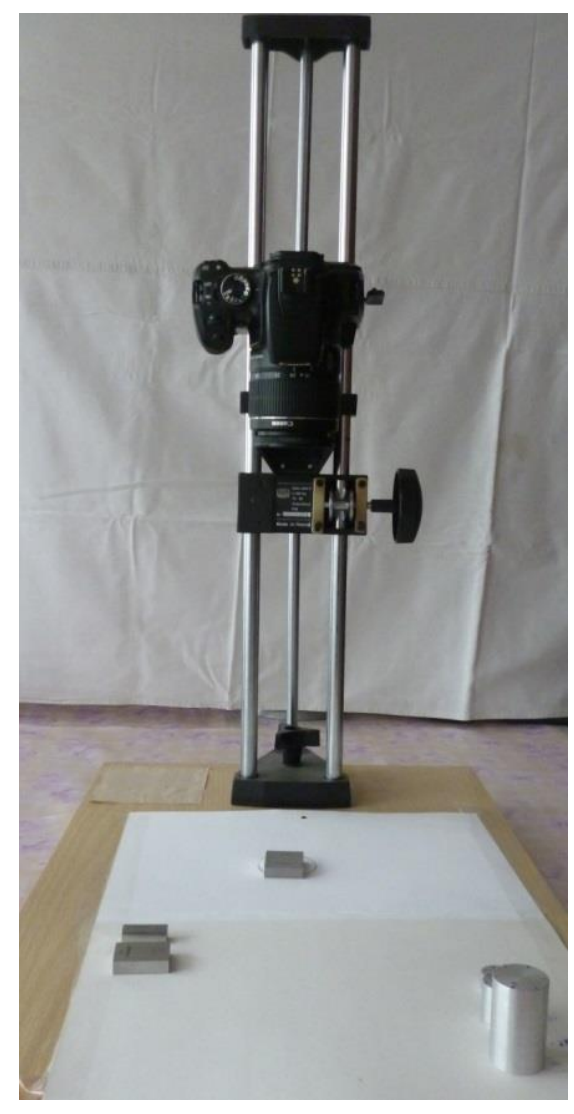

Figure 2. Unit for experimental capturing of the calibers and details digital model of the object and increase its accuracy. In this study an experiment to determine the effect of distance from the object to the matrix of the shooting techniques $L$ on generalizations coefficient of performance $\mathrm{KT}$ is conducted.

\section{EXPERIMENTAL DETAILS}

A study to identify the impact of the correction coefficient $K_{L}$ is conducted, that takes into account the influence of the distance from the object to the matrix of the shooting techniques. For this purpose unit which provide the ability to read the movements of the shooting technique to capture objects is developed. To measure the distance from the object to the camera matrix is used standard vernier height gauge with accuracy 0,02mm (Figure 2).

Canon camera with a standard lens is used as shooting equipment. It is maintained a constant focal length $f=18 \mathrm{~mm}$ and constant environmental conditions - temperature and light. The gauge blocks 10,25 and 30 are captured in distances from $\mathrm{L}=240 \mathrm{~mm}$ to $\mathrm{L}=665 \mathrm{~mm}$ at intervals of $25 \mathrm{~mm}$. The pictures are processed in "Microsoft Visio 2010" and the computing and graphical interpretation of the results are carried out in "Microsoft Excel 2010".

For any distance the objects are photographed 40 times and then the values obtained of measurements in pixels are averaged and are presented in Table 1. By formula (2) are calculated the coefficients of the 


\section{IRTITE}

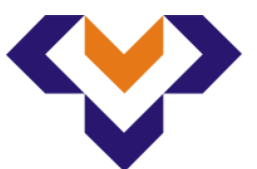

Ipplied Reseitrones in Technics, Technologies and Bductition

Journal of the Faculty of Technics and Technologies, Trakia University https://sites.google.com/a/trakia-uni.bg/artte/

transform for each gauge block for the investigated distance.

The obtained results are graphically processed. On Figure 3 are shown dependencies between the measured dimensions in pixels and the distance from the matrix of shutting techniques to the objects. Figure 4 shows the resulting models to determine the coefficient of performance, taking into account the distance from the object to the camera matrix $\mathrm{K}_{\mathrm{L}}$ depending on the size of shutting object and distance $L$. Trend lines that describe the nearest theoretical distribution of experimental data determined by visual comparison of available "Microsoft Excel 2010" models are built.

It was found that the experimental data are described most accurately by depending on the type $y=a_{1} \cdot x^{a_{2}}$. The obtained coefficients of determination $\mathrm{R}^{2}$ of each model is greater than 0.99 (Figure 4). From this figure it is seen that there is a strong correlation between the coefficient of $K_{L}$ and the distance $L$, which is confirmed by the high value of $R^{2}$ for all three distributions. The obtained relations are described with power functions whose nature is similar and functions are convergent.

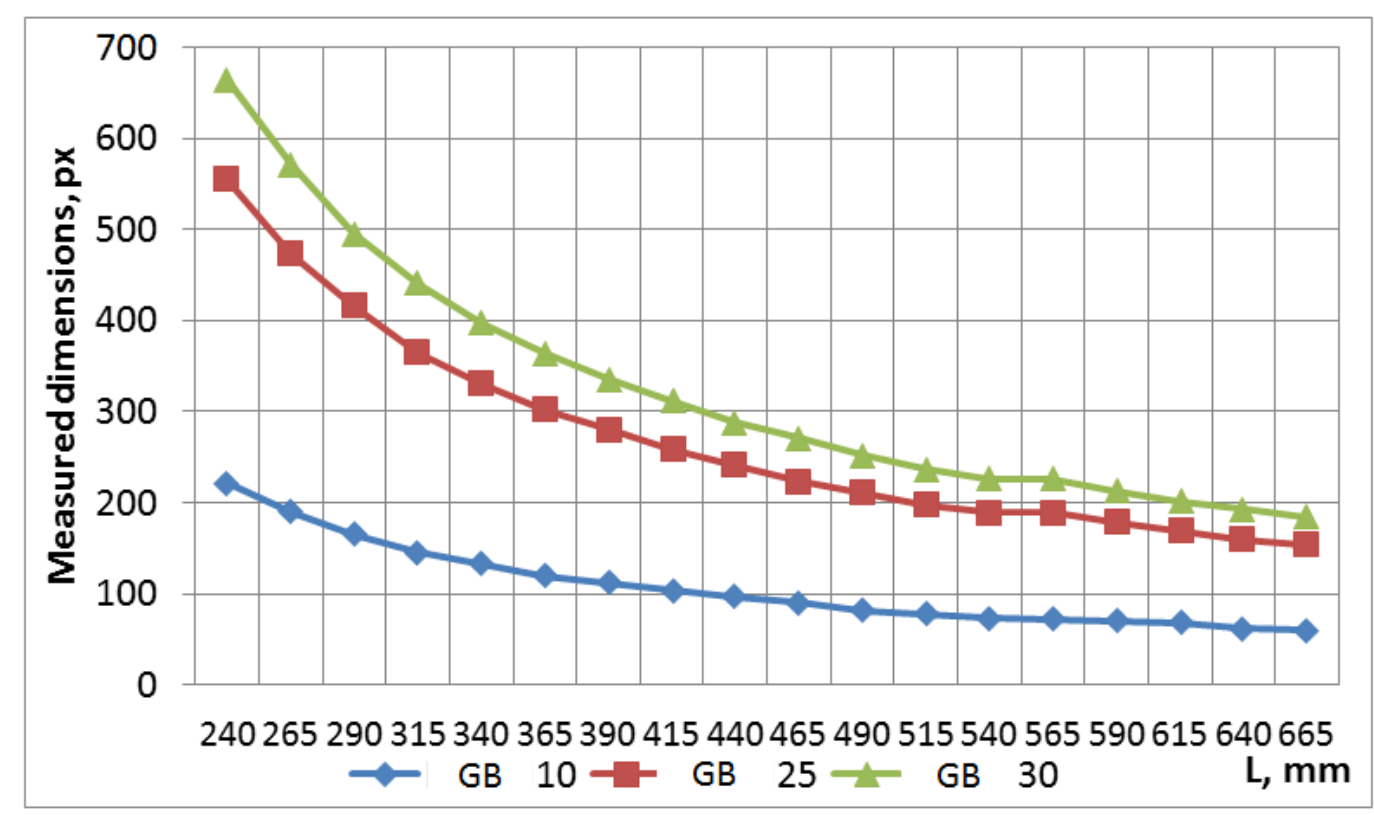

Figure 3.

Dependence for the measured dimensions of the gauges from the distance $L$ to the matrix of the camera

\section{RESULTS}

For validation of the resulting equations are conducted experiments to determine their practical applicability to obtain a specific dimension. It is found that the received error, depending on the value of $L$ reaches $10 \%$. The error is smallest in the middle of the range of $\mathrm{L}$ and increases towards the edges of the considered range. This shows that there are other factors that have an impact and further study is needed to establish their degree of impact on received error. 
Table 1. Values of the measured dimensions in pixels and the calculated $\mathrm{KL}$

\begin{tabular}{|c|c|c|c|c|c|c|}
\hline $\begin{array}{c}\mathrm{L}, \\
\mathrm{mm}\end{array}$ & $\begin{array}{c}\text { Measured } \\
\text { dimensions } \\
\text { for gauge } \\
\text { block } 10, \mathrm{px}\end{array}$ & $\begin{array}{c}\text { Calculated } \\
\mathbf{k}_{110} \\
\text { px/mm }\end{array}$ & $\begin{array}{c}\text { Measured } \\
\text { dimensions } \\
\text { for gauge } \\
\text { block } 25, \mathrm{px}\end{array}$ & $\begin{array}{c}\text { Calculated } \\
\mathrm{K}_{\mathrm{L} 25}, \\
\mathrm{px} / \mathrm{mm}\end{array}$ & \begin{tabular}{|c|} 
Measured \\
dimensions \\
for gauge \\
block 30, px \\
\end{tabular} & $\begin{array}{c}\text { Calculated } \\
\mathrm{K}_{\mathrm{L} 30}, \\
\mathrm{px} / \mathrm{mm}\end{array}$ \\
\hline 240 & 221.787 & 22.1787 & 555 & 22.2 & 665.0001 & 22.16667 \\
\hline 265 & 190.263 & 19.0263 & 472.537 & 18.90148 & 570.7749 & 19.02583 \\
\hline 290 & 165.68 & 16.568 & 416.083 & 16.64332 & 495.9081 & 16.53027 \\
\hline 315 & 145.538 & 14.5538 & 365.137 & 14.60548 & 441.0219 & 14.70073 \\
\hline 340 & 133.427 & 13.3427 & 330.946 & 13.23784 & 396.1089 & 13.20363 \\
\hline 365 & 120.142 & 12.0142 & 302.174 & 12.08696 & 363.8781 & 12.12927 \\
\hline 390 & 111.087 & 11.1087 & 280.284 & 11.21136 & 335.436 & 11.1812 \\
\hline 415 & 103.417 & 10.3417 & 258.276 & 10.33104 & 311.9409 & 10.39803 \\
\hline 440 & 96.699 & 9.6699 & 240.052 & 9.60208 & 287.6739 & 9.58913 \\
\hline 465 & 90.9 & 9.09 & 224.39 & 8.9756 & 270.4041 & 9.01347 \\
\hline 490 & 81.875 & 8.1875 & 210.279 & 8.41116 & 252.3339 & 8.41113 \\
\hline 515 & 78.028 & 7.8028 & 197.797 & 7.91188 & 237.33129 & 7.911043 \\
\hline 540 & 72.887 & 7.2887 & 189.069 & 7.56276 & 226.2069 & 7.54023 \\
\hline 565 & 72.293 & 7.2293 & 188.599 & 7.54396 & 225.7461 & 7.52487 \\
\hline 590 & 69.763 & 6.9763 & 178.895 & 7.1558 & 213.042 & 7.1014 \\
\hline 615 & 68.071 & 6.8071 & 168.247 & 6.72988 & 201.1719 & 6.70573 \\
\hline 640 & 62.223 & 6.2223 & 159.796 & 6.39184 & 192.39 & 6.413 \\
\hline 665 & 60.036 & 6.0036 & 153.327 & 6.13308 & 184.4211 & 6.14737 \\
\hline
\end{tabular}

\section{CONCLUSIONS}

As a conclusion from this study can be formulated following conclusions:

- On the value of coefficient of performance $\mathrm{K}_{\mathrm{T}}$ significantly affect the coefficient takes into account the distance from the object to the camera matrix $\mathrm{K}_{\mathrm{L}}$;

- The nature of the dependence is a power function which is reliable demonstrated by the high values of the coefficient of determination;

- The size of the captured objects influence on the received coefficient $K_{L}$ which is demonstrated by the different coefficients and exponents in the resulting equations;

- It is found that various placements of the shooting objects affect on the obtaining measurement values, but its establishment requires further research;

- The selected focal length $f=18 \mathrm{~mm}$, which is the smallest for the used lens, gives minimal filling the matrix with graphic information for research object and reporting error of the size is large, in view of the fact that it is described by a smaller number of pixels;

- In the practical validation of the obtained equations the preparation of relatively large and irregular error in studies range is established which indicates the presence of other confounding factors;

- Received error is greater at the ends of research range of distances between your subject and the matrix of capturing equipment and decreases to its middle, which implies conducting further experiments in more narrow range;

- It is imperative autofocus of the camera be turned off when capturing because different measure values would be received, which is a prerequisite for mandatory control this factor.

IRTIIE Vol. 4, No. 4, 2016 ISSN 1314-8788 (print), ISSN 1314-8796 (online), doi: 10.15547/artte.2016.04.004 


\section{IRTTIE}

Ipplied Researl'ches in Technics, Technologies ind Bducation Journal of the Faculty of Technics and Technologies, Trakia University https://sites.google.com/a/trakia-uni.bg/artte/

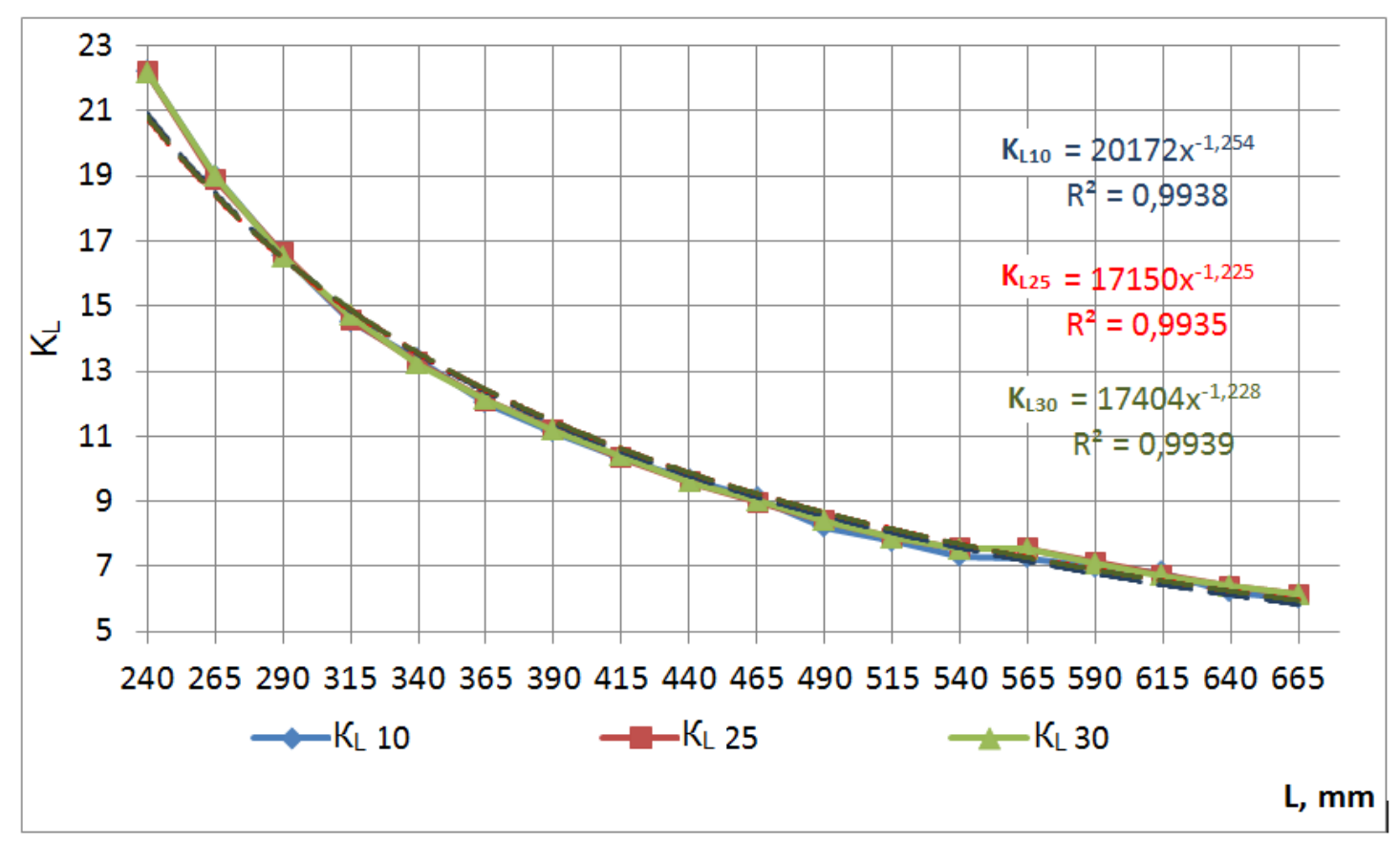

Figure 4. Dependence of the $K_{L}$ from the distance $L$ to the matrix camera

\section{REFERENCES}

[1] Karamanov A. G. Photogrammetry, Saint Petersburg national research university of informatics, technologies, mechanics and optic, Saint Petersburg, 2012, pp.171, e-book, http://open.ifmo.ru/.

[2] Maldjanski PI. Benefits of digital photogrammetry to the analogue photogrammetric technologies, International jubilee scientific and practical conference UASG2012, 15-17 November 2012.

[3] Sakakushev B., T. Todorov. Possibility to determine the distance to the object by stereo photogrammetry. International scientific conference - Theoretical and practical aspects of the development of modern science, VI International scientific and practical conference, Moskva, 26.12.2012, 2013, volume 6, pp. 111-116.

[4] Sakakushev B., V. Grigorov, G. Georgiev. Methodology for determining the distance to an object using a stereo photogrammetry, International scientific conference - Theoretical and practical aspects of the development of modern science, VIII International scientific and practical conference, Moskva, 29 June 2013 Scientific Information publishing center "Institute for Strategic Studies". Moskva: Publishing center "Spetskniga", 2013, pp. 77-80.

[5] Bryman Alan, Triangulation, Encyclopedia of Social Science Research Methods, SAGE Publications, 08.11.2011, http://www.referenceworld.com.

[6] Fryer J. G. Introduction, in: Close Range Photogrammetry and Machine Vision, Whittles Publishing, Roseleigh House, Latheronwheel, Caithness, KW5 6DW, Scotland, 2000, pp. $1-7$.

[7] Gruen A. Development of digital methodology and systems, in: Close Range Photogrammetry and Machine Vision, Whittles Publishing, Roseleigh House, Latheronwheel, Caithness, KW5 6DW, Scotland, UK, 2000, pp. 78-104.

[8] Gruen A. Development of digital methodology and systems, in: Close Range Photogrammetry and Machine Vision, Whittles Publishing, Roseleigh House, Latheronwheel, Caithness, KW5 6DW, Scotland, UK, 2000, pp. 78-104.

IRTIIE Vol. 4, No. 4, 2016 ISSN 1314-8788 (print), ISSN 1314-8796 (online), doi: 10.15547/artte.2016.04.004 